\title{
Pedogenic, mineralogical and land-use controls on organic carbon stabilization in two contrasting soils
}

\author{
A. F. Plante ${ }^{1}$, I. Virto ${ }^{2}$, and S. S. Malhi ${ }^{3}$ \\ ${ }^{1}$ Department of Earth \& Environmental Science, University of Pennsylvania, Philadelphia PA 19104-6316, USA; \\ ${ }^{2}$ Área Edafología y Química Agrícola, Departamento Ciencias del Medio Natural, Universidad Pública de Navarra, \\ Campus Arrosadia, 31006 Pamplona, Spain; and ${ }^{3}$ Agriculture and Agri-Food Canada, P.O. Box 1240, Melfort, \\ Saskatchewan, Canada SOE 1AO. Received 2 June 2009, accepted 15 October 2009.
}

\begin{abstract}
Plante, A. F., Virto, I. and Malhi, S. S. 2010. Pedogenic, mineralogical and land-use controls on organic carbon stabilization in two contrasting soils. Can. J. Soil Sci. 90: 15-26. Organo-mineral complexation in soils is strongly controlled by pedogenesis, but the mechanisms controlling it and its interaction with cultivation are not yet well understood. We compared the mineralogy and quality of organic carbon (C) among organo-mineral fractions from two soils with contrasting pedogenic origin. Sequential density fractionation (SDF; using 1.6, 1.8, 2.1, 2.4 and $2.6 \mathrm{~g} \mathrm{~mL}^{-1} \mathrm{sodium}$ polytungstate solutions) followed by thermal analysis was applied to a Chernozem from Ellerslie, Alberta, and a Luvisol from Breton, Alberta, each under native and cultivated land uses. Similar clay mineralogy suggested that pedogenic controls on organic $\mathrm{C}$ stabilization were related to long-term vegetation cover. In addition to large differences in total organic $\mathrm{C}$ quantities, bulk soil and isolated fractions showed significant differences in organic $\mathrm{C}$ quality. Samples under native vegetation revealed greater organo-mineral complexation at Ellerslie compared with Breton, as expressed by less solubilisation, more organic $\mathrm{C}$ recovered in intermediate-density fractions, and exothermic differential scanning calorimetry peak signals associated with more stable forms of organic C. Long-term cultivation resulted in an overall shift to more stable organo-mineral complexes. The proportion of soil $\mathrm{C}$ in the $2.1-2.4 \mathrm{~g} \mathrm{~mL}^{-1}$ fraction increased under cultivation from 21 to $32 \%$ in Breton samples, and from 6 to 16\% in Ellerslie samples. The quality of inherited pedogenic soil organic $\mathrm{C}$ stored in a soil thus appears to determine its response to long-term cultivation.
\end{abstract}

Key words: Cultivation, sequential density fractionation, organic carbon, organic matter, thermal analysis

\begin{abstract}
Plante, A. F., Virto, I. et Malhi, S. S. 2010. Contrôle de la stabilisation du carbone organique dans deux sols contrastants par la pédogenèse, la minéralogie et l'exploitation des terres. Can. J. Soil Sci. 90: 15-26. La création de complexes organominéraux dans les sols est largement régie par la pédogenèse, mais on comprend mal les mécanismes qui la commandent et ses interactions avec l'agriculture. Les auteurs ont comparé la minéralogie et la qualité du carbone organique (C) dans les fractions organo-minérales de deux sols d'origine contrastante. Pour cela, ils ont appliqué le fractionnement par gradient de densité (avec des solutions renfermant 1,6, 1,8, 2,1, 2,4 et 2,6 g de polytungstate de sodium par $\mathrm{mL}$ ) puis l'analyse thermique à un tchernoziom d'Ellerslie (Alberta) et à un luvisol de Breton (Alberta), à l'état naturel et cultivé, dans chaque cas. Une minéralogie similaire de l'argile laisse croire que le contrôle exercé par la pédogenèse sur la stabilisation du C organique est associé à une couverture végétale prolongée. Outre les importantes variations au niveau de la concentration totale de $\mathrm{C}$ organique, le sol brut et les fractions qui en ont été isolées présentent des écarts sensibles au niveau de la qualité du $\mathrm{C}$ organique. Ainsi, les échantillons du sol sur lequel poussait la végétation naturelle présentaient plus de complexes organo-minéraux à Ellerslie qu'à Breton, comme l'indiquent une moins grande solubilisation, la récupération d'une quantité accrue de $\mathrm{C}$ organique dans les fractions à densité intermédiaire et les pics exothermiques de l'analyse calorimétrique à compensation de puissance associés aux formes plus stables de $\mathrm{C}$ organique. La culture à long terme entraîne un déplacement général vers des complexes organo-minéraux plus stables. La proportion de $\mathrm{C}$ dans la fraction de 2,1 à $2.4 \mathrm{~g}$ par $\mathrm{mL}$ est passée de 21 à $32 \%$ dans les échantillons prélevés sur les sols cultivés à Breton, et de 6 à $16 \%$ dans ceux d'Ellerslie. La qualité du C organique hérité de la pédogenèse et stocké dans le sol semble donc déterminer la réaction de ce dernier à une culture prolongée.
\end{abstract}

Mots clés: Culture, fractionnement par gradient de densité, carbone organique, matière organique, analyse thermique

Important progress has been made in the last decade in understanding the processes of organic carbon (C) stabilization in soils. Three interdependent mechanisms have been identified: occlusion within aggregates, biochemical stabilization (recalcitrance), and the formation of organo-mineral complexes (Sollins et al. 1996; von Lützow et al. 2006). Organo-mineral complexation is acknowledged as a long-term form of soil organic matter (SOM) stabilization (Kaiser and Guggenberger
2003), and mineral-bound organic matter normally accounts for most of the soil $\mathrm{C}$ in most agricultural soils (Hassink 1997). However, the mechanisms of

Abbreviations: DSC, differential scanning calorimetry; SDF, sequential density fractionation; SOM, soil organic matter; SPT, sodium polytungstate 
organo-mineral complex formation and stabilization in soils are not yet well understood. Since both the organic and mineral phases of soils are involved, differences in both mineralogy and organic matter composition could account for the observed differences in organo-mineral complexes in different soils (Denef and Six 2005; Denef and Six 2006; Wattel-Koekkoek and Buurman 2004; Wattel-Koekkoek et al. 2003).

Organo-mineral associations range from uncomplexed free organic and mineral particles in the soil matrix with minimal direct interaction, to essentially inseparable organo-mineral complexes. This results in a range of particles of different densities within the soil. Density fractionation has been used for many years to separate SOM that is more or less strongly associated with minerals. Sequential density fractionation (SDF) has been demonstrated to be useful for identifying mechanisms of organo-mineral interactions and quantifying pools of organic matter with different ecological roles that are relevant to soil organic matter research (Crow et al. 2007; Swanston et al. 2005). Several authors have applied SDF techniques to different soils (Baisden et al. 2002; Basile-Doelsch et al. 2007; Shang and Tiessen 2001; Sollins et al. 2006) using different heavy liquids and density cut-offs. The method is based on the lesser density of the organic phase of the soil in comparison with the mineral phase (Sollins et al. 2006), which implies that organo-mineral mixtures richer in organic materials are lighter than the organic matter-poor heavier ones. Using a density of $1.4 \mathrm{~g} \mathrm{~cm}^{-3}$ for the organic phase (Adams 1973; Mayer et al. 2004) and $2.6 \mathrm{~g} \mathrm{~cm}^{-3}$ for the mineral phase, Chenu and Plante (2006) calculated the SOM contents of organo-mineral particles using a simple mixing model. The model can thus be used to select densities to separate materials that are predominantly organic, organo-mineral mixtures, or predominantly mineral using anticipated SOM concentrations.

It is well known that cultivation generally results in SOM losses. Differences exist, however, in the response of different soil types to cultivation, not only in terms of quantity, but also in terms of the quality of SOM remaining in the soil after cultivation (Janzen 2005). Here, SOM quality refers to how easily carbon in the soil organic matter can be mineralized (sensu Bosatta and Agren 1999). Changes in the quantity and quality of SOM in response to cultivation are likely a function of the pedogenic origin of the soil. We can assume that differences in mineralogy, as well as the nature of the organic matter entering the soil (e.g., grassland versus forest vegetation) and in the manner in which it enters the soil (e.g., mostly as surface litter inputs vs. incorporation at depth by root turnover) can result in different types of organo-mineral complexes. However, the influence of pedogenesis on the stabilization of SOM of different pedogenic origin under similar climatic conditions is still unclear. In addition, the effect of cultivation on such complexes and its interaction with soil pedogenic properties remains mostly unknown.
The objective of this study was to compare the mineralogy and quality of organic $\mathrm{C}$ among organomineral fractions of increasing density in two agricultural soils of contrasting pedogenic origin but under similar management and climatic conditions in Alberta (Canada), to better understand mechanisms of SOM stabilization in soils.

\section{MATERIALS AND METHODS Soils and Experimental Sites}

Two soils were selected for this study: an Orthic Gray Luvisol (Typic Cryoboralf) of the Breton loam series located in the rolling landscape of the vicinity of Breton, Alberta, and an Orthic Black Chernozem (Typic Cryoboroll) of the Malmo loam series common to the flat lacustrine landscape near Ellerslie, Alberta. These two soils are only $\sim 70 \mathrm{~km}$ apart and have very similar climatic conditions, but represent two major and distinctly different soil types found in north-central Alberta. Descriptive data of both soils are given in Table 1.

Parallel long-term experiments were established at each site in 1979 to examine the interactive effect of tillage (no-till and conventional tillage), $\mathrm{N}$ fertility $\left(0\right.$ and $\left.56 \mathrm{~kg} \mathrm{~N} \mathrm{ha}^{-1} \mathrm{yr}^{-1}\right)$ and residue management (straw removed or left on the soil) (Nyborg et al. 1995). The treatments in both field experiments were laid out as randomized complete blocks with four replicates. In 2007 ( $28 \mathrm{yr}$ after the initiation of the experiment), 10 surface $(0-15 \mathrm{~cm})$ soil cores $(2.4 \mathrm{~cm}$ diameter $)$ were taken from each plot (experimental unit) and bulked into a composite sample. Samples were then air-dried and ground to pass a 2-mm sieve. For this study, three treatment-replicate samples were randomly selected from the available samples because previous experiments demonstrated relatively minor differences in $\mathrm{C}$ storage among the samples from different experimental treatments at Breton (Plante et al. 2006). In 2008, three field replicates of native (never cultivated) surface soil $(0-15 \mathrm{~cm})$ were collected from adjacent woodlots from each site.

\section{Sequential Density Fractionation}

The density of a given organo-mineral complex is a function of the density of the mineral phase, the density of the organic phase, the relative contributions of the mineral and organic phases, and the porosity of the organo-mineral particle. Our objective was to focus on dispersed primary particles (as defined by soil texture), thus removing porosity by applying high energy sonication. Preliminary experiments determined the minimum energy needed for complete dispersion (i.e., equivalent to textural particle-size distribution) of the soil samples (Schmidt et al. 1999). However, to prevent the potential fragmentation and redistribution of coarse particulate organic matter (Roscoe et al. 2000), the first density fraction was isolated in a two-step process (Fig. 1). 


\begin{tabular}{|c|c|c|c|c|}
\hline & \multicolumn{2}{|c|}{ Breton } & \multicolumn{2}{|c|}{ Ellerslie } \\
\hline & Native & Cultivated & Native & Cultivated \\
\hline Location & \multicolumn{2}{|c|}{ lat. $53^{\circ} 5^{\prime} 22^{\prime \prime} \mathrm{N}$, long. $114^{\circ} 26^{\prime} 33^{\prime \prime} \mathrm{W}$} & \multicolumn{2}{|c|}{ lat. $53^{\circ} 25^{\prime} 12^{\prime \prime} \mathrm{N}$, long. $113^{\circ} 32^{\prime} 50^{\prime \prime} \mathrm{W}$} \\
\hline Ecoregion & \multicolumn{2}{|c|}{ Boreal Transition } & \multicolumn{2}{|c|}{ Aspen Parkland } \\
\hline $\mathrm{MAT}^{\mathbf{z}}$ & \multicolumn{2}{|c|}{$2.1^{\circ} \mathrm{C}$} & \multicolumn{2}{|c|}{$1.7^{\circ} \mathrm{C}$} \\
\hline MAP $^{y}$ & \multicolumn{2}{|c|}{$547 \mathrm{~mm}$} & \multicolumn{2}{|c|}{$452 \mathrm{~mm}$} \\
\hline Soil classification & \multicolumn{2}{|c|}{ Orthic Gray Luvisol } & \multirow{2}{*}{\multicolumn{2}{|c|}{ Orthic Black Chernozem }} \\
\hline Texture & \multicolumn{2}{|c|}{$220 \mathrm{~g}^{\text {clay } \mathrm{kg}^{-1} \text { soil }}$} & & \\
\hline $\mathrm{pH}$ & $6.64 \pm 0.01$ & $6.39 \pm 0.12$ & $6.55 \pm 0.01$ & $6.73 \pm 0.06$ \\
\hline Total organic $\mathrm{C}\left(\mathrm{g} \mathrm{C} \mathrm{kg}^{-1}\right.$ soil) & $26 \pm 3$ & $9 \pm 1$ & $118 \pm 2$ & $51 \pm 1$ \\
\hline Total $\mathrm{N}$ ( $\mathrm{g} \mathrm{N} \mathrm{kg}^{-1}$ soil) & $1.8 \pm 0.2$ & $0.9 \pm 0.03$ & $8.0 \pm 0.04$ & $4.5 \pm 0.09$ \\
\hline $\mathrm{C}: \mathrm{N}$ ratio & $14.4 \pm 0.2$ & $9.6 \pm 0.5$ & $14.7 \pm 0.1$ & $11.4 \pm 0.2$ \\
\hline
\end{tabular}

${ }^{\mathbf{z}} \mathrm{MAT}=$ mean annual temperature.

${ }^{\mathrm{y}} \mathrm{MAP}=$ mean annual precipitation .

For each sample, $20 \mathrm{~g}$ of air-dry soil was evenly split into two $50-\mathrm{mL}$ centrifuge bottles, $30 \mathrm{~mL}$ of deionized $\mathrm{H}_{2} \mathrm{O}$ was added to each bottle, and the bottles were vigorously shaken (vortex shaker, $3 \mathrm{~min}$ ) until the soil was homogenously wetted. The mixture was then centrifuged for $40 \mathrm{~min}$ at $11400 \times g$ (equivalent to $10000 \mathrm{rpm}$ in a fixed-angle glass-fibre rotor in a Beckmann J2-21 centrifuge), so that all particles less dense than water, or particles less dense than $1.6 \mathrm{~g}$ $\mathrm{mL}^{-1}$ and also $<0.1 \mu \mathrm{m}$ in equivalent diameter were recovered in suspension. Floating materials were aspirated from the centrifuge bottle and rinsed with $150 \mathrm{~mL}$ of $0.1 \mathrm{M} \mathrm{CaCl}_{2}$ on a $0.45 \mu \mathrm{m}$ glass-fibre filter, thus isolating a non-occluded $<1.0 \mathrm{~g} \mathrm{~mL}^{-1}$ fraction.

Samples were re-suspended in deionised water (total volume $40 \mathrm{~mL}$ ) and sonicated in an ice bath for $7.5 \mathrm{~min}$ at $50 \%$ pulse for a total input of $400 \mathrm{~J} \mathrm{~mL}^{-1}$ using a Model 500 sonic dismembrator $(\max$. output $=400 \mathrm{~W}$, Fisher Scientific). Materials attached to the probe were rinsed into the bottle, and the mixture was again centrifuged at $11400 \times g$ for $40 \mathrm{~min}$. Floating materials (occluded light particles) were aspirated from the bottle and rinsed with $100 \mathrm{~mL} 0.1 \mathrm{M} \mathrm{CaCl}_{2}$ on a glass fibre filter. Rinsing was accelerated by vacuum suction. This occluded $<1.0 \mathrm{~g} \mathrm{~mL}^{-1}$ fraction and the previous nonoccluded fraction were transferred to weighed tin capsules and oven-dried $\left(50^{\circ} \mathrm{C}\right)$. The mass proportion of the $<1.0 \mathrm{~g} \mathrm{~mL}^{-1}$ fractions was negligible and these fractions were not included in subsequent analyses.

Subsequent density fractionation was accomplished by means of centrifugation of samples suspended in solutions of sodium polytungstate (SPT). We selected density limits at $1.6,1.8,2.1,2.4$ and $2.6 \mathrm{~g} \mathrm{~mL}^{-1}$. At each step, $30 \mathrm{~mL}$ of the corresponding SPT solution was added to the heavy portion of the preceding fraction, the mixture was re-suspended by vortex shaking (3 $\mathrm{min}$ ), then centrifuged. The light fraction was recovered by aspiration and poured into a $500-\mathrm{mL}$ centrifuge bottle, to which $400 \mathrm{~mL}$ of distilled water was added for rinsing by centrifugation. We avoided the use of filters to recover density fractions, following the advice of Baisden et al. (2002). This procedure was repeated twice at each density point to remove SPT, and the aspirated materials for the three cycles for a given density were combined. This ensured complete recovery of each density fraction, because the possible dilution of SPT by the residual lighter medium in the first cycle of each fraction was offset by the second and third cycles. The density of SPT was regularly tested by pipetting and weighing $1 \mathrm{~mL}$ of the solution remaining after each third cycle, and was always found to remain within $\pm 0.05 \mathrm{~g}$ $\mathrm{mL}^{-1}$ of the density limits set in our protocol. To avoid cross-contamination between density fractions, we used freshly prepared SPT solutions at every step of the fractionation protocol, and for every individual sample. SPT powder was also analyzed for any $\mathrm{C}$ and $\mathrm{N}$ contamination (Kramer et al. 2009) and found to be negligible.

Centrifugation conditions in SPT were determined using Stoke's law and took into account the increased viscosity and density of SPT liquids. Centrifugation times and relative centrifugal fields $(g)$ were set such that particles remaining in floatation were less dense than the SPT solution or were $<0.2 \mu \mathrm{m}$ in equivalent diameter, and had a maximum density corresponding to the following density fraction, except for the heaviest density fraction, for which we increased the size limit to $0.7 \mu \mathrm{m}$. Samples were centrifuged for $85 \mathrm{~min}$ at $11400 \times g$ in $1.6 \mathrm{~g}$ $\mathrm{mL}^{-1}$ and $1.8 \mathrm{~g} \mathrm{~mL}^{-1} \mathrm{SPT}$, for $105 \mathrm{~min}$ at $11400 \times g$ in $2.1 \mathrm{~g} \mathrm{~mL}^{-1} \mathrm{SPT}$, for $240 \mathrm{~min}$ at $10000 \times g$ in $2.4 \mathrm{~g} \mathrm{~mL}^{-1}$ SPT, and for $120 \mathrm{~min}$ at $11400 \times g$ in $2.6 \mathrm{~g} \mathrm{~mL}^{-1} \mathrm{SPT}$. Rinsing of the fractions with distilled water by centrifugation was done at $11400 \times g$ for $40 \mathrm{~min}$ each time. All density fractions were oven-dried $\left(50^{\circ} \mathrm{C}\right)$, weighed and gently hand-ground by mortar and pestle to $<150 \mu \mathrm{m}$ for subsequent analyses. 


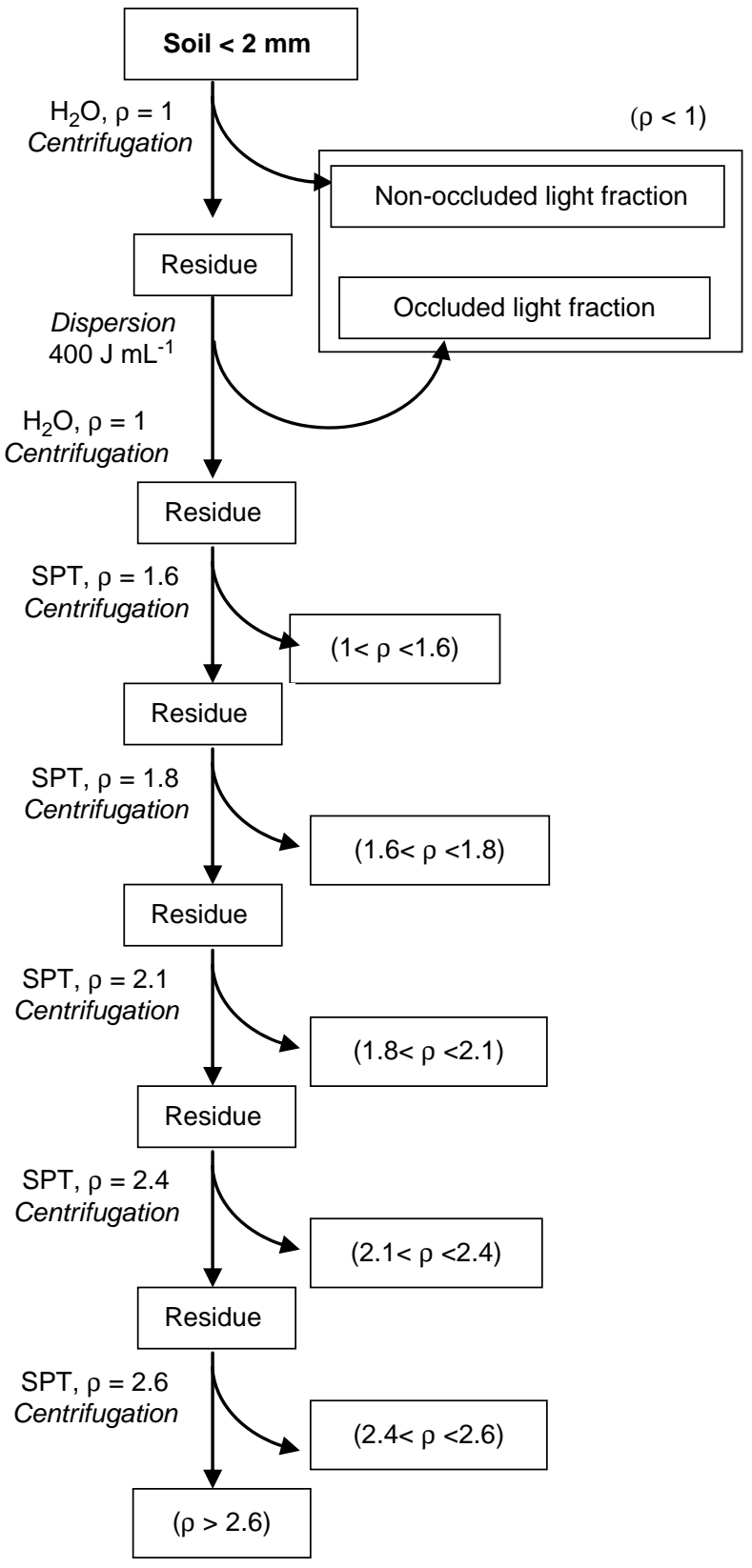

Fig. 1. Schematic diagram of the sequential density fraction (SDF) procedure.

\section{Mineralogical Analyses}

Bulk clay-sized fractions were isolated from cultivated soils from each site using a dispersion procedure similar to that described above. Ten grams of soil and $40 \mathrm{~mL}$ of de-ionized water were combined in a $50 \mathrm{~mL}$ centrifuge tube and mixed using a vortex mixer for $\sim 1 \mathrm{~min}$. The suspension was sonicated in an ice bath for $7.5 \mathrm{~min}$ at $50 \%$ pulse for a total input of $400 \mathrm{~J} \mathrm{~mL}^{-1}$. Two dispersed suspensions were combined and diluted in a $500 \mathrm{~mL}$ cylinder, and allowed to stand for $4 \mathrm{~h}$ and 50 min to allow $>2 \mu \mathrm{m}$ diameter particles to sediment. The suspension in the top $7 \mathrm{~cm}$ of the cylinder was transferred to aluminum dishes and dried at $50^{\circ} \mathrm{C}$. The dried clay-sized fraction was ground to $<150 \mu \mathrm{m}$.

Differences in mineralogy between the two soils were assessed by analyzing the bulk clay fractions of the cultivated soils from the two sites. Mineralogy of each density fraction isolated from the two cultivated soils was assessed to characterize the mineral component of the fractions. Mineralogy was determined by X-ray diffraction with a PANanalytical X'Pert Pro instrument using $\mathrm{Cu}-\mathrm{K} \alpha$ radiation at $45 \mathrm{kV}$ and $40 \mathrm{~mA}$. Diffraction patterns were recorded from $5-75^{\circ} 2 \theta$ with the sample spinning at one revolution per $16 \mathrm{~s}$.

\section{Thermal and Elemental Analyses}

Bulk soil and isolated density fractions were subjected to thermal analysis to characterize the organo-mineral complexes using a Netzsch STA 409PC Luxx simultaneous thermal analyzer equipped with a type-S TG-DSC sample carrier supporting a PtRh10-Pt thermocouple (Netzsch-Gerätebau GmbH, Selb, Germany). Thermal analysis consisted of heating samples from ambient to $700^{\circ} \mathrm{C}$ at a rate of $10^{\circ} \mathrm{C} \mathrm{min}^{-1}$. Samples were placed in a Pt crucible, and an identical and empty crucible was used as the reference. For consistency across density fractions, sample masses were adjusted to analyze approximately $1.5 \mathrm{mg}$ of organic C. Samples were heated under an oxidizing atmosphere of $30 \mathrm{~mL}$ $\min ^{-1}$ of synthetic air $\left(20 \% \mathrm{O}_{2}\right.$ and $\mathrm{N}_{2}$ balance) and $10 \mathrm{~mL} \min ^{-1}$ of $\mathrm{N}_{2}$ as a protective gas in the instrument. The instrument was previously calibrated for temperature and enthalpy sensitivity using the melting points of several materials, and calcium oxalate was periodically used as a check. Differential scanning calorimetry (DSC) data were corrected for baseline drift using the non-parametric baseline fitting function of Peakfit software by setting the region $>600^{\circ} \mathrm{C}$ equal to baseline and allowing the program to determine the remaining baseline.

Different patterns in the DSC thermograms suggest the presence of organic matter with different composition, quality or stability (De la Rosa et al. 2008; Lopez-Capel et al. 2005b; Plante et al. 2005). Previous studies have reported thermogravimetric mass losses of labile organic matter (between 180 and $380^{\circ} \mathrm{C}$ ), recalcitrant organic matter (between 380 and $475^{\circ} \mathrm{C}$ ), and refractory organic matter (including black $\mathrm{C}$, between 475 and $650^{\circ} \mathrm{C}$ ) (De la Rosa et al. 2008). These mass losses are often referred to as $\mathrm{Exo}_{1}, \mathrm{Exo}_{2}$, and $\mathrm{ExO}_{3}$, and are expressed as relative proportions of the total weight loss $\left(\mathrm{Exo}_{\text {tot }}\right.$, between 180 and $\left.650^{\circ} \mathrm{C}\right)$. We elected to combine the latter two pools and use only labile $\left(\% \mathrm{Exo}_{1}, \quad 180-380^{\circ} \mathrm{C}\right)$ and recalcitrant $\left(\% \mathrm{ExO}_{23}, 380-650^{\circ} \mathrm{C}\right)$ thermogravimetric mass losses, as in Dell'Abate et al. (2003) and Plante et al. (2005), because DSC peaks from most isolated density fractions were frequently centered rather than separated near $475^{\circ} \mathrm{C}$. Results are reported as the ratio of 
a)

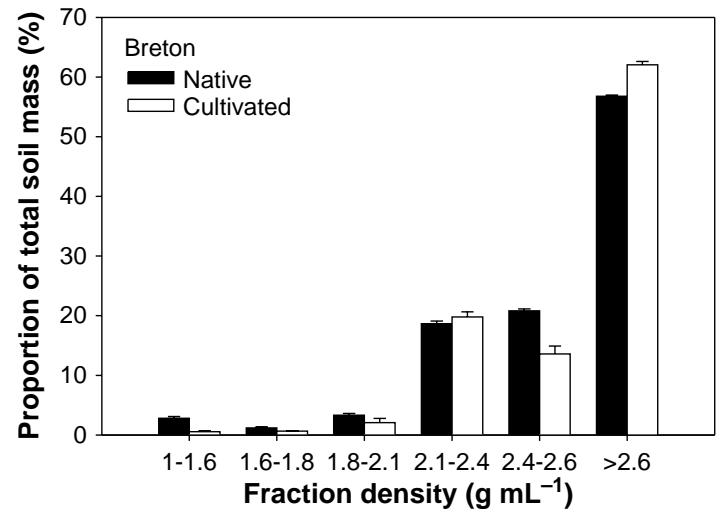

b)

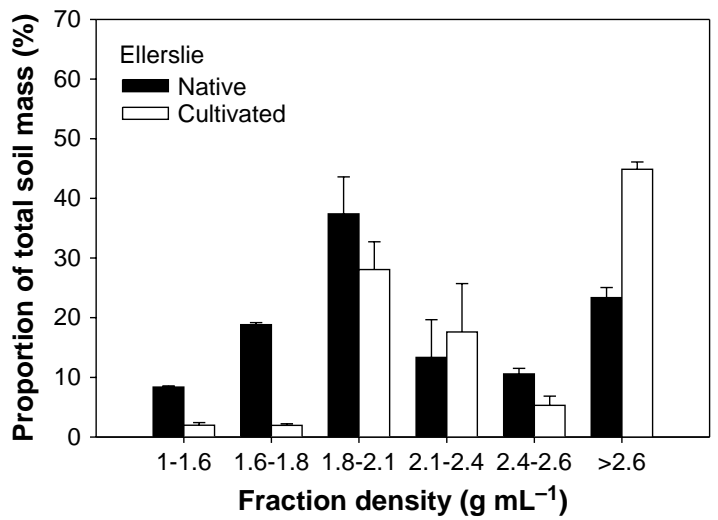

Fig. 2. Mass distribution of density fractions isolated from native and cultivated soils from (a) Breton and (b) Ellerslie, Alberta, Canada. Error bars represent standard error of the mean.

$\% \mathrm{Exo}_{1}$ to $\% \mathrm{Exo}_{23}$, similar to Dell'Abate et al. (2000) and Lopez-Capel et al. (2005a,b), such that values $>1$ indicate more than half of the SOM is thermally labile, while decreasing values indicate an increasing proportion of thermally stable material.

Total $\mathrm{C}$ and $\mathrm{N}$ concentrations of the whole soil and each isolated fraction were analyzed using a CN 1100 autoanalyzer (Carlo Erba Instruments, Milan, Italy). Results of acid additions for the presence of soil carbonates indicated that carbonates were not present, and thus total $\mathrm{C}$ concentrations were equated to total organic $\mathrm{C}$ concentrations.

\section{Statistical Analyses}

Whole-soil organic $\mathrm{C}$ concentration and $\mathrm{C}: \mathrm{N}$ ratio data were analyzed using a two-way ANOVA with site and land use as the main effects. Differences between means were considered different when $P<0.05$ unless otherwise indicated, and post-hoc analyses were performed by Duncan tests. Organic C (data not shown), C:N ratio and $\% \mathrm{Exo}_{1} / \mathrm{OExO}_{23}$ data were analyzed for each siteland use combination by one-way ANOVA due to significant interaction terms. For each site, data were first analyzed for differences among density fractions within each land use, then for differences between land uses within each density fraction. All statistical analyses were performed using SPSS 16.0 software (SPSS Inc., Chicago IL).

\section{RESULTS}

\section{Mass and C Distributions in Density Fractions}

Whole-soil total organic C concentration was significantly greater in native samples than in cultivated samples at both Breton and Ellerslie sites (Table 1). In addition, whole-soil total organic $\mathrm{C}$ concentration decreased from 26 to $9 \mathrm{~g} \mathrm{C} \mathrm{kg}^{-1}$ at Breton, and from 118 to $51 \mathrm{~g} \mathrm{C} \mathrm{kg}^{-1}$ at Ellerslie. This indicated a substantial loss in native organic $\mathrm{C}$ due to long-term cultivation in both soils, but proportional losses in soil organic $\mathrm{C}$ were greater at Breton $(65 \%)$ than at Ellerslie $(57 \%)$. The trends for whole-soil total $\mathrm{N}$ were similar to total organic $\mathrm{C}$, with percentage loss of total $\mathrm{N}$ due to cultivation $50 \%$ at Breton and 44\% at Ellerslie (Table 1). Whole-soil C:N ratio for the native soil was similar for Ellerslie and Breton, but greater than cultivated soil at both sites. The $\mathrm{C}: \mathrm{N}$ ratio in the cultivated soil was significantly greater for Ellerslie than Breton.

Mass recoveries during SDF were satisfactory for all soils, ranging from $98.7 \pm 0.6 \%$ in Breton cultivated samples to $111.9 \pm 2.8 \%$ in Ellerslie native samples. Mass recoveries greater than $100 \%$ suggest that some SPT contamination might have occurred due to incomplete rinsing (Basile-Doelsch et al. 2007). Variability among replicates was small in the Breton samples, but more significant in the Ellerslie samples (Fig. 2). Variability in the intermediate densities of the Ellerslie samples suggests a significant amount of material near the selected density cut-off. Distributions of fraction masses differed among soils and treatments. In both cultivated soils the heaviest fraction $\left(>2.6 \mathrm{~g} \mathrm{~mL}^{-1}\right)$ represented the largest proportion of the soil mass: $62.0 \pm 0.6 \%$ for Breton and $44.9 \pm 1.2 \%$ for Ellerslie. The heaviest fraction also represented the largest proportion of mass in the Breton native samples $(56.8 \pm 0.2 \%)$, but the largest proportion in the Ellerslie native samples was in the $1.8-2.1 \mathrm{~g} \mathrm{~mL}^{-1}$ fraction $(37.4 \pm 6.2 \%)$.

Calculations of $\mathrm{C}$ recoveries showed significant losses of soil C during SDF. Solubilised C losses represented $23.0 \pm 8.1 \%$ of initial soil $\mathrm{C}$ for Breton native, $8.7 \pm 2.5 \%$ for Breton cultivated, $16.0 \pm 3.5 \%$ for Ellerslie native, and $15.2 \pm 1.7 \%$ for Ellerslie cultivated samples. In spite of the losses, sequential density fraction succeeded in separating each soil into three types of particles. The predominantly organic fractions $\left(1-1.6\right.$ and $\left.1.6-1.8 \mathrm{~g} \mathrm{~mL}^{-1}\right)$ had $\mathrm{C}$ concentrations greater than $100 \mathrm{mg} \mathrm{C} \mathrm{g}^{-1}$ fraction. Organo-mineral fractions (1.8-2.1 and 2.1-2.4 g $\mathrm{mL}^{-1}$ ) had $\mathrm{C}$ concentrations between 10 and $100 \mathrm{mg}$ $\mathrm{C}^{-1}$ fraction. The predominantly mineral fractions 
(2.4-2.6 and $>2.6 \mathrm{~g} \mathrm{~mL}^{-1}$ ) had $\mathrm{C}$ concentrations less than $10 \mathrm{mg} \mathrm{C} \mathrm{g}^{-1}$ fraction (data not shown).

Patterns of $\mathrm{C}$ distribution across the density fractions differed among soils and treatments (Fig. 3). Generally, native soils had the greatest proportion of $\mathrm{C}$ in one of the predominantly organic fractions, while cultivated soils had the greatest proportion of $\mathrm{C}$ in one of the organo-mineral fractions. Taken together, the two predominantly mineral fractions represented less than $5 \%$ of total soil $\mathrm{C}$, with the exception of the Breton cultivated samples, which contained $16.5 \pm 2.7 \%$ of total soil C. The C:N ratios of the fractions decreased significantly in all soils with increasing density (Table 2), as was usually observed in previous soil SDF studies (Baisden et al. 2002; Sollins et al. 2006). The C:N ratios were generally greater in Breton samples compared with Ellerslie samples, with the exception of the predominantly mineral fractions (Table 2 ). $C: N$ ratios of the 2.4-2.6 $\mathrm{g} \mathrm{mL}^{-1}$ fraction were significantly greater for the cultivated treatment compared with the native treatment of both soils $(P<0.10)$, and did not differ between soils within treatments. The $>2.6 \mathrm{~g} \mathrm{~mL}^{-1}$ fraction showed no differences between the two cultivated soils, while $\mathrm{C}: \mathrm{N}$ ratios could not be determined for the native soils because $\mathrm{N}$ concentrations were below detection limits.

\section{Mineralogical Analyses}

Despite differences in pedogenetic origins, clay mineralogy was similar between the cultivated soils from the two sites (Fig. 4). This fraction was dominated mostly by quartz, with a significant presence of smectite and some kaolinite and illite. Overall, few differences were observed in the mineralogy of individual density fractions between the cultivated soils (Fig. 5a, b). In both soils, the presence of organic matter in the lightest fractions interfered with XRD analysis of the minerals. The presence of residual SPT also seemed to have altered the smectite region in the X-ray diffractograms

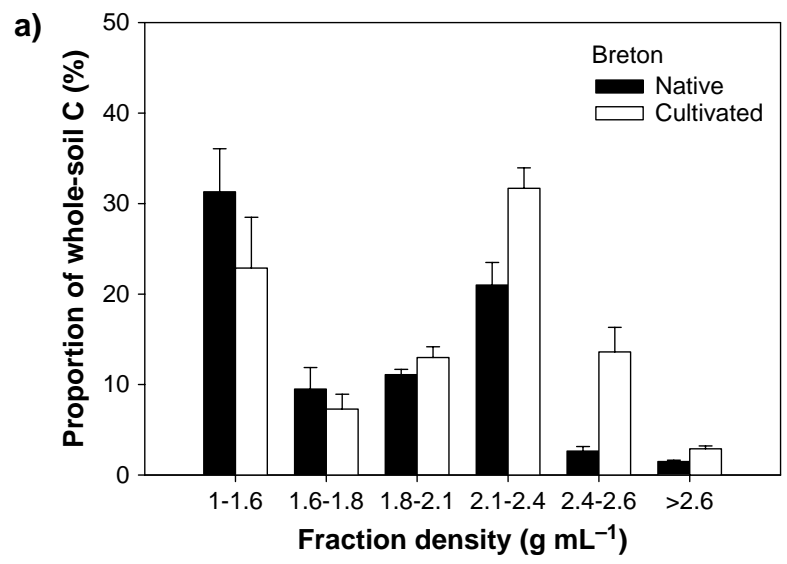

of the fractions of intermediate-density (1.8-2.1 and 2.1$2.4 \mathrm{~g} \mathrm{~mL}^{-1}$ at Breton, and $1.8-2.1 \mathrm{~g} \mathrm{~mL}^{-1}$ at Ellerslie), seen as a broad curve upward in the region where the primary smectite peak should have occurred. The smectite peaks were slightly visible only in the heaviest fractions of the Breton soil (2.4-2.6 and $>2.6 \mathrm{~g}$ $\left.\mathrm{mL}^{-1}\right)$. Quartz was the dominant mineral in the heaviest fractions of both soils, and was also observed in all density fractions of both soils.

\section{Thermal Analyses}

As already observed in earlier studies on thermal analysis of soil materials (Dell'Abate et al. 2003; Grisi et al. 1998; Siewert 2004), thermogravimetric mass losses in the complete exothermic region $\left(\mathrm{Exo}_{\text {tot }}\right)$ were highly correlated to sample organic C concentrations (Fig. 6). While a linear regression explained a large proportion of the variability $\left(r^{2}=0.98\right)$, an exponential rise to a limit relationship provided a better $\left(r^{2}=0.99\right)$ and more intuitive fit. Distributions of mass losses between $\mathrm{Exo}_{1}$ and $\mathrm{Exo}_{23}$ (expressed as their ratio) indicate that organic C stability differed among soils and treatments (Table 3). Interestingly, thermal stability of soil organic $\mathrm{C}$ did not increase or decrease monotonically with increasing density, but was least (i.e., highest ratio value) in organo-mineral samples of density $1.8-2.1 \mathrm{~g}$ $\mathrm{mL}^{-1}$ in both soils and $2.1-2.4 \mathrm{~g} \mathrm{~mL}^{-1}$ in Ellerslie.

Observed DSC patterns (Figs. 7 and 8) were consistent with previously published results (e.g., Lopez-Capel et al. 2005b; Plante et al. 2005), and consisted of an endothermic region between ambient temperature and $150^{\circ} \mathrm{C}$ due to the release of water, and an exothermic region between 180 and $600^{\circ} \mathrm{C}$ comprised of two or three more-or-less distinct peaks due to the oxidation of organic matter. A small endothermic peak near $573^{\circ} \mathrm{C}$ is due to the $\alpha-\beta$ inversion of quartz (Barwood and Hajek 1979). Whole-soil samples revealed significantly different patterns in DSC thermograms among soils and treatments (Fig. 7), suggesting that soil organic $\mathrm{C}$
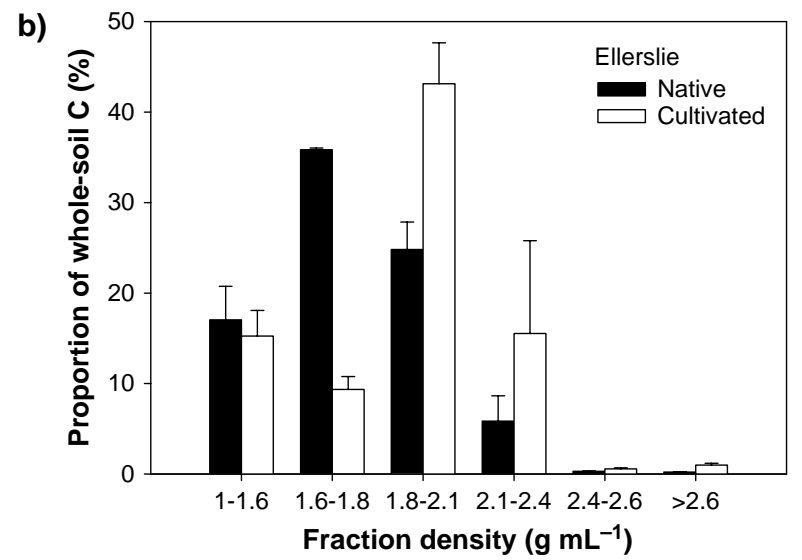

Fig. 3. Organic C distribution of density fractions isolated from native and cultivated soils from (a) Breton and (b) Ellerslie, Alberta, Canada. Error bars represent standard error of the mean. 


\begin{tabular}{|c|c|c|c|c|c|c|c|}
\hline & & $1-1.6$ & $1.6-1.8$ & $1.8-2.1$ & $2.1-2.4$ & $2.4-2.6$ & $>2.6$ \\
\hline \multirow[t]{2}{*}{ Breton } & Native & $23.5 \pm 0.3_{* * * *}^{* *} a$ & $18.7 \pm 0.3^{*} b$ & $12.9 \pm 0.3 c$ & $8.7 \pm 0.02^{* * *} d$ & $3.9 \pm 0.2^{*} e$ & ND \\
\hline & Cultivated & $29.1 \pm 1.0^{* * *} a$ & $16.4 \pm 0.9^{*} b$ & $12.8 \pm 1.7 c$ & $6.4 \pm 0.7^{* *} d$ & $6.0 \pm 0.9^{*} d e$ & $3.0 \pm 0.3 e$ \\
\hline \multirow[t]{2}{*}{ Ellerslie } & Native & $17.6 \pm 1.4 a$ & $14.7 \pm 0.1 b$ & $11.3 \pm 0.1^{* *} c$ & $10.9 \pm 0.4^{* *} c$ & $3.5 \pm 0.1^{*} d$ & ND \\
\hline & Cultivated & $19.7 \pm 0.2 a$ & $15.4 \pm 0.5 b$ & $9.6 \pm 0.3^{* *} c$ & $8.2 \pm 0.6^{* *} c$ & $4.9 \pm 0.6^{*} d$ & $3.7 \pm 0.7 d$ \\
\hline
\end{tabular}

*** Within columns for each site separately values are significantly different at $P<0.05$ and $P<0.10$, respectively, among treatments (cultivated vs. native).

$a-e$ ithin rows, values followed by different letters belong to different Duncan's homogeneous groups $(P<0.05)$.

quality differed between soils, and was also altered by land use change. Significant differences in DSC thermograms were also observed among density fractions for a given soil, suggesting the SDF separated particles with significantly different organic $\mathrm{C}$ qualities. Perhaps more importantly, DSC thermograms of each density fraction differed among soils and treatments (Fig. 8). The height of the exothermic region is directly related to organic $\mathrm{C}$ concentration, such that analyses of predominantly mineral fractions $\left(2.4-2.6\right.$ and $\left.>2.6 \mathrm{~g} \mathrm{~mL}^{-1}\right)$ resulted in almost no exothermic signal and therefore results are not shown in Fig. 8.

a)

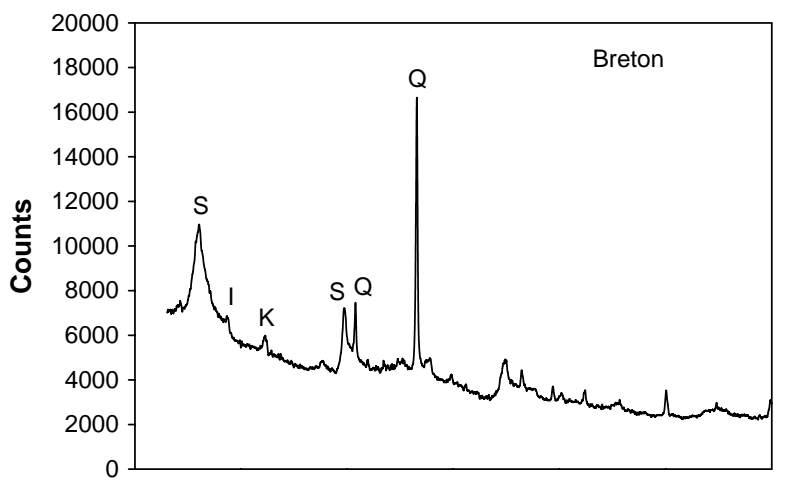

b)

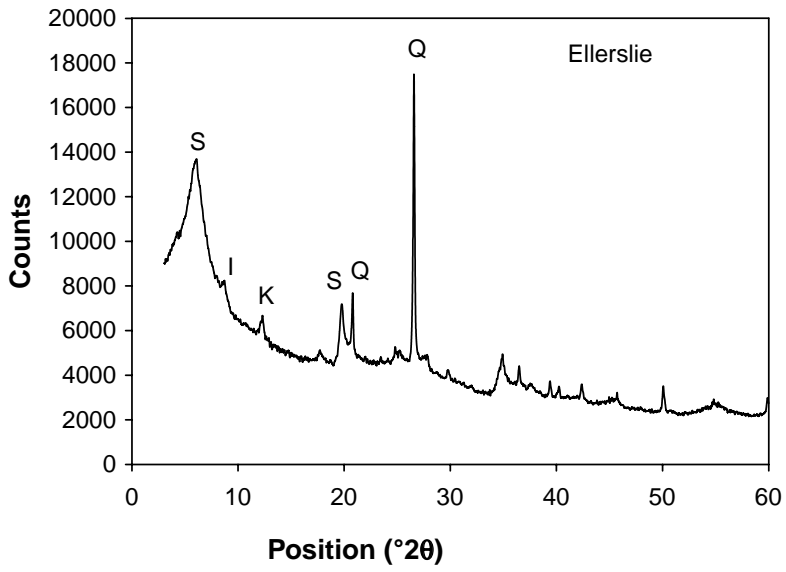

Fig. 4. X-ray diffractograms of bulk clay-sized fractions $(<2$ $\mu \mathrm{m}$ ) isolated from cultivated soils from (a) Breton and (b) Ellerslie, Alberta, Canada. $\mathrm{S}=$ smectite, $\mathrm{I}=$ illite, $\mathrm{K}=$ kaolinite, $\mathrm{Q}=$ quartz.

\section{DISCUSSION}

The two soils examined in this study were chosen because they are relatively close to each other $(\sim 70$ $\mathrm{km})$, and subject to very similar climatic conditions. They have also been subject to the same tillage, fertilization and residue management regimes during recent decades (Nyborg et al. 1995). They do, however, have differing pedogenic origins (Crown and Greenlee 1978). The soil at Breton was formed over till derived from Tertiary sediments of the Paskapoo Formation, while the soil at Ellerslie was formed over fine-textured lacustrine sediments from Proglacial Lake Edmonton that overlie till derived from the Upper Cretaceous Edmonton Formation. In terms of native vegetation over the past $4000-6000 \mathrm{yr}$, Breton is in the Boreal Transition ecoregion of the Boreal Plain, which is predominantly a deciduous boreal forest of trembling aspen, while Ellerslie is in the Aspen Parkland ecoregion of the Prairies, which is classified as transitional fescue grassland interspersed by trembling aspen groves. Samples collected under native vegetation were collected from woodlots at both sites. These stands currently have similar tree stem densities and species compositions (data not shown) but the histories of land cover are unknown and may have changed with some frequency particularly at Ellerslie.

While a discussion of the complete pedogenic histories of these two soils is beyond the scope of this study, the outcomes of these differing histories are significant differences in not only the quantity of soil organic $\mathrm{C}$, but also the quality of soil organic $\mathrm{C}$ as shown by their responses to cultivation, amounts of $\mathrm{C}$ solubilised during SDF, mass and $\mathrm{C}$ distributions among the density fractions, $\mathrm{C}: \mathrm{N}$ ratios, and results of thermal analyses. The lack of significant differences in clay mineralogy between sites (Fig. 4) suggests that the differences in surface soil organic $\mathrm{C}$ are not likely due to parent material, but probably related to differences in long-term vegetation cover that resulted in different quantities and qualities of organic matter inputs and soil-plant-water dynamics.

\section{Breton and Ellerslie Native Samples}

Aside from the striking difference in whole-soil organic $\mathrm{C}$ quantity $\left(26 \pm 3 \mathrm{~g} \mathrm{C} \mathrm{kg}^{-1}\right.$ at Breton versus $118 \pm 2 \mathrm{~g} \mathrm{C}$ $\mathrm{kg}^{-1}$ at Ellerslie), SDF and thermal analysis revealed 
(a)
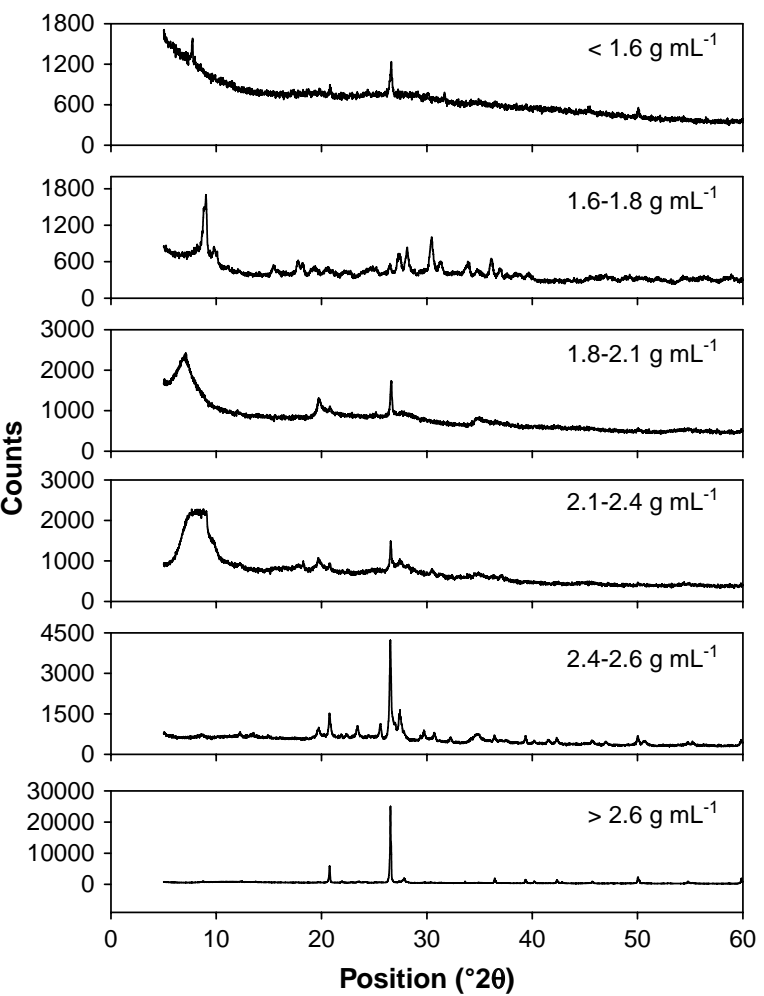

(b)

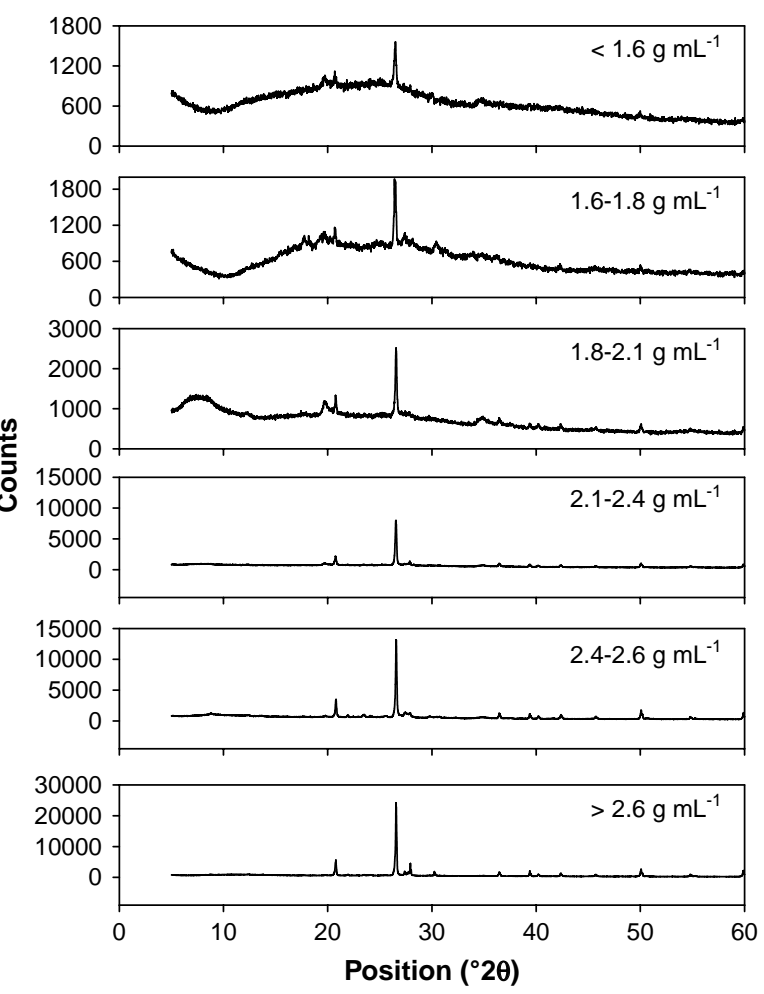

Fig. 5. X-ray diffractograms of density fractions isolated from cultivated soils from (a) Breton and (b) Ellerslie, Alberta, Canada. Note that scale of y-axis differs between sites for the 2.1-2.4 $\mathrm{g} \mathrm{mL}^{-1}$ and $2.4-2.6 \mathrm{~g} \mathrm{~mL}^{-1}$ fractions.

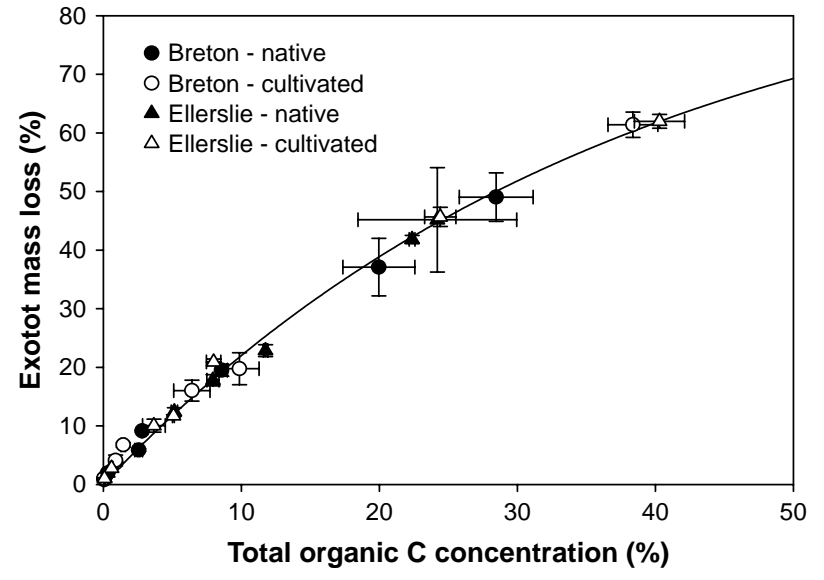

Fig. 6. Relationship between soil total organic carbon concentration and mass loss in the exothermic region $\left(\mathrm{ExO}_{\text {tot }}, 180\right.$ $650^{\circ} \mathrm{C}$ ) of native and cultivated soils from Breton and Ellerslie, Alberta, Canada. Error bars represent standard error of the mean.

significant differences in soil organic $\mathrm{C}$ quality between soils under native vegetation from the two sites. Soluble organic C losses during density fractionation in SPT solutions are frequent (Crow et al. 2007) and attributable to water-soluble $\mathrm{C}$ and organic compounds solubilised by the dispersive effect of the high $\mathrm{Na}$ concentration in SPT solutions. A greater proportion of soil organic $\mathrm{C}$ was solubilised during fractionation of Ellerslie samples compared with Breton samples, providing a first indication of differences in soil organic $\mathrm{C}$ quality between the soils because water soluble organic C is typically considered labile (Haynes 2005). While the mass distribution of fractions after SDF of Breton native soil samples was skewed to mineraldominated heavy fractions (Fig. 2a), the largest proportion of $\mathrm{C}$ was found in the lightest fraction (Fig. 3a). This $\mathrm{C}$ distribution in Breton was very similar to the one observed by Sollins et al. (2006) in the surface soil of a forest andic Inceptisol in Oregon. Conversely, the mass and $\mathrm{C}$ distributions of Ellerslie samples were dominated by fractions of intermediate density (Fig. $2 b$ and $3 b$ ). The results suggest greater organo-mineral complexation in Ellerslie samples compared with Breton samples, which several researchers have associated with greater long-term stabilization (e.g., Eusterhues et al. 2003). Evidence from thermal analyses of soils under native vegetation also points to greater soil organic $\mathrm{C}$ stability at Ellerslie compared with Breton. Peak DSC signals of whole-soil samples were observed near $330^{\circ} \mathrm{C}$ for Breton and near $375^{\circ} \mathrm{C}$ for Ellerslie samples (solid lines in Fig. 7). The DSC peaks of each isolated density fraction were also at higher temperatures for Ellerslie compared with Breton samples (solid lines in Fig. 8), with the exception of the $1-1.6 \mathrm{~g} \mathrm{~mL}^{-1}$ fraction where no significant differences were observed. Higher DSC 
Table 3. Thermogravimetric mass losses of whole-soil samples and isolated density fractions (mean \pm standard error, $n=3$ ) of soils from two locations in Alberta, Canada

\begin{tabular}{|c|c|c|c|c|c|}
\hline & \multirow[b]{2}{*}{ Fraction $\left(\mathrm{g} \mathrm{mL}^{-1}\right)$} & \multicolumn{2}{|c|}{ Exo $_{\text {tot }}\left(\%\right.$ mass loss, $\left.180-650^{\circ} \mathrm{C}\right)$} & \multicolumn{2}{|c|}{$\% \operatorname{Exo}_{1} / \% \operatorname{Exo}_{23}^{\mathrm{z}}\left(180-380^{\circ} \mathrm{C} / 380-650^{\circ} \mathrm{C}\right)$} \\
\hline & & Native & Cultivated & Native & Cultivated \\
\hline \multirow[t]{7}{*}{ Breton } & Whole soil & $5.9 \pm 0.2$ & $3.7 \pm 0.1$ & $1.029^{* *}$ & $0.682^{* *}$ \\
\hline & $1-1.6$ & $49.0+4.1$ & $61.4+2.2$ & $0.574^{* *} c$ & $0.451^{* *} d$ \\
\hline & $1.6-1.8$ & $37.1 \pm 4.9$ & $19.8 \pm 2.7$ & $0.809^{*} b$ & $0.658^{*} a b$ \\
\hline & $1.8-2.1$ & $19.5 \pm 1.0$ & $16.0 \pm 1.8$ & $0.987^{* * *} a$ & $0.773^{* *} a$ \\
\hline & $2.1-2.4$ & $9.1 \pm 0.2$ & $6.8 \pm 0.4$ & $0.703^{* *} b$ & $0.572^{* *} b c$ \\
\hline & $2.4-2.6$ & $2.0 \pm 0.1$ & $4.1 \pm 0.9$ & $0.381^{* *} d$ & $0.483^{* *} c d$ \\
\hline & $>2.6$ & $0.8 \pm 0.0$ & $1.0 \pm 0.1$ & $0.380 d$ & $0.386 d$ \\
\hline \multirow{7}{*}{ Ellerslie } & Whole soil & $22.8 \pm 1.0$ & $11.7 \pm 0.2$ & $1.262^{* *}$ & $1.059^{* *}$ \\
\hline & $1-1.6$ & $45.2 \pm 8.9$ & $62.0 \pm 1.2$ & $0.570^{* *} a$ & $0.474^{* *} b c$ \\
\hline & $1.6-1.8$ & $41.8 \pm 0.7$ & $45.7 \pm 1.6$ & $0.593^{*} a$ & $0.520^{*} b$ \\
\hline & $1.8-2.1$ & $17.8 \pm 1.0$ & $20.9 \pm 1.1$ & $0.621 a$ & $0.690 a$ \\
\hline & $2.1-2.4$ & $12.4 \pm 0.7$ & $10.0 \pm 0.1$ & $0.616^{* *} a$ & $0.782^{* *} a$ \\
\hline & $2.4-2.6$ & $2.0 \pm 0.1$ & $2.8 \pm 0.1$ & $0.369^{* *} b$ & $0.522^{* *} b$ \\
\hline & $>2.6$ & $1.1 \pm 0.1$ & $1.0 \pm 0.1$ & $0.371 b$ & $0.381 \mathrm{c}$ \\
\hline
\end{tabular}

${ }^{\mathbf{z}}$ Lower values indicate greater thermal stability.

*, **Within rows, values are significantly different at $P<0.05$ and $P<0.10$, respectively, among treatments (cultivated vs. native).

$a-d$ Within columns for each site separately, values followed by different letters belong to different Duncan's homogeneous groups $(P<0.05)$.

a)

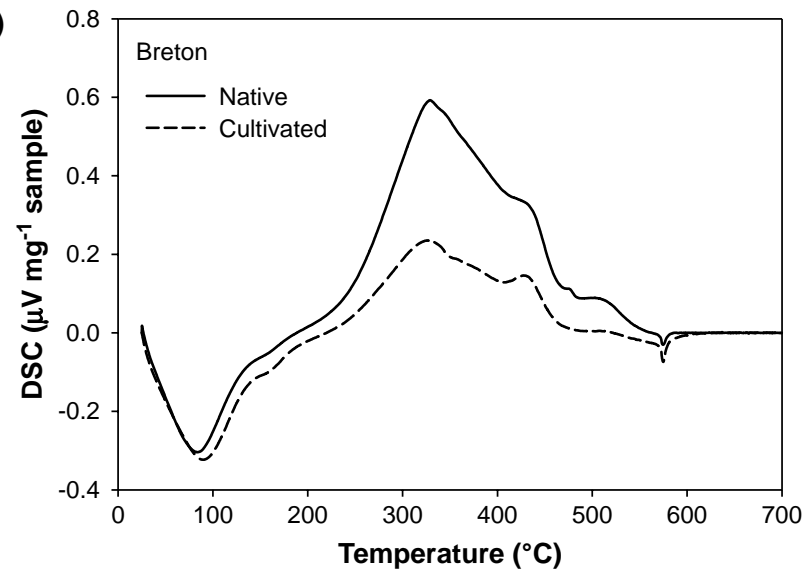

b)

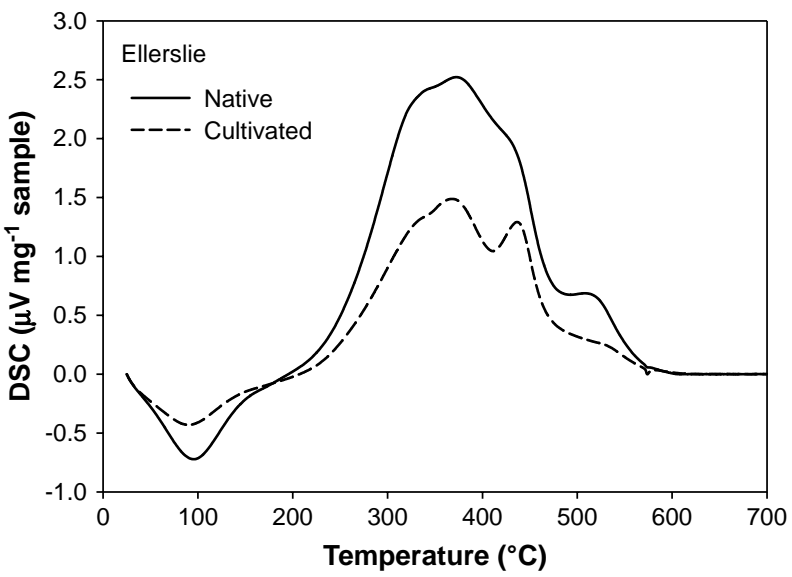

Fig. 7. Differential scanning calorimetry (DSC) thermograms of native and cultivated whole-soil samples from (a) Breton and (b) Ellerslie, Alberta, Canada. peak temperatures were also associated with smaller ratios of $\% \mathrm{Exo}_{1}$ to $\% \mathrm{ExO}_{23}$ for isolated density fractions from Ellerslie compared with Breton samples (Table 3). Given greater soil organic C stability in organo-mineral complexes from Ellerslie compared with Breton, we would expect differential responses of these soils to long-term cultivation.

\section{Responses to Cultivation}

As a proportion of initial soil $\mathrm{C}$, long-term cultivation resulted in greater losses of organic $\mathrm{C}$ at Breton $(\sim 65.4 \%)$ than at Ellerslie $(\sim 57 \%)$. In addition to reductions in soil organic C quantity, SDF and thermal analyses revealed significant differences in soil organic $\mathrm{C}$ stability after cultivation for both soils. Reduced DSC peak heights for cultivated whole-soil samples reflect reduced soil organic $\mathrm{C}$ concentrations (Fig. 7). However, differences in peak heights were greater at $330-350^{\circ} \mathrm{C}$ than they were at $430-450^{\circ} \mathrm{C}$ for both sites, suggesting losses were greater for more thermally labile SOM. In addition, $\% \mathrm{Exo}_{1} / \% \mathrm{Exo}_{23}$ values for whole-soil samples from both sites were smaller for cultivated samples than their native counterparts (Table 3), indicating an enrichment in more stable soil organic C. A greater proportional decrease in the values due to cultivation for the Breton soil provides further evidence for greater stability of the original soil organic $\mathrm{C}$ in the native Ellerslie soil.

These reductions in quantity and changes in stability at the whole-soil level were associated with shifts in the distribution of mass and $\mathrm{C}$ among isolated density fractions (Figs. 2 and 3), towards more soil mass and $\mathrm{C}$ recovered in heavier fractions. These were similar to previous observations in a SDF study conducted by Roscoe et al. (2000) on changes in soil organic C 
a)

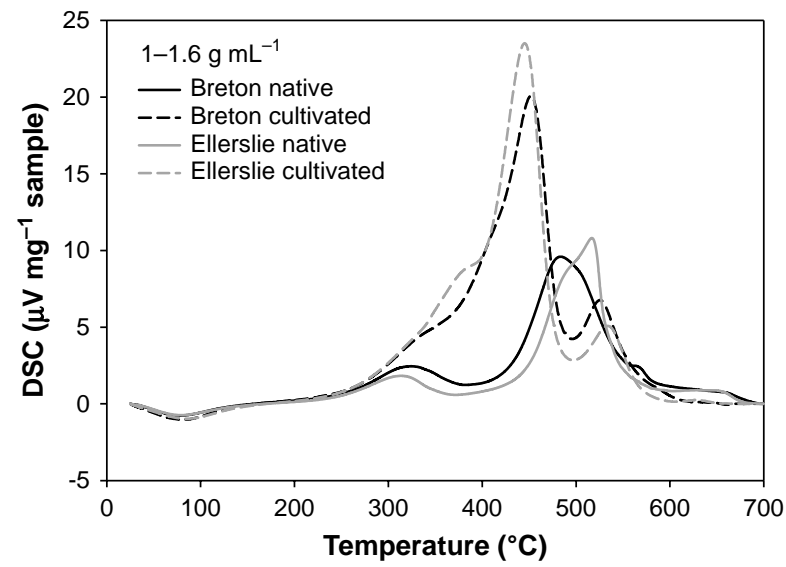

c)

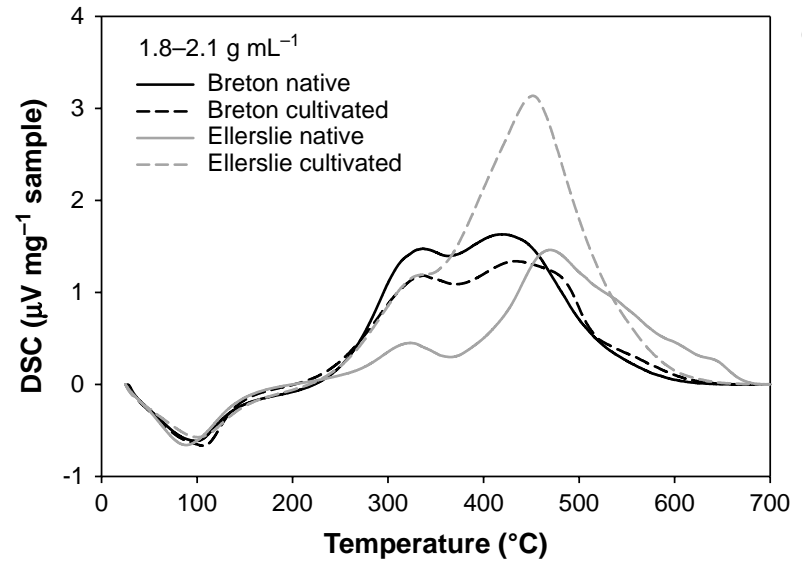

b)

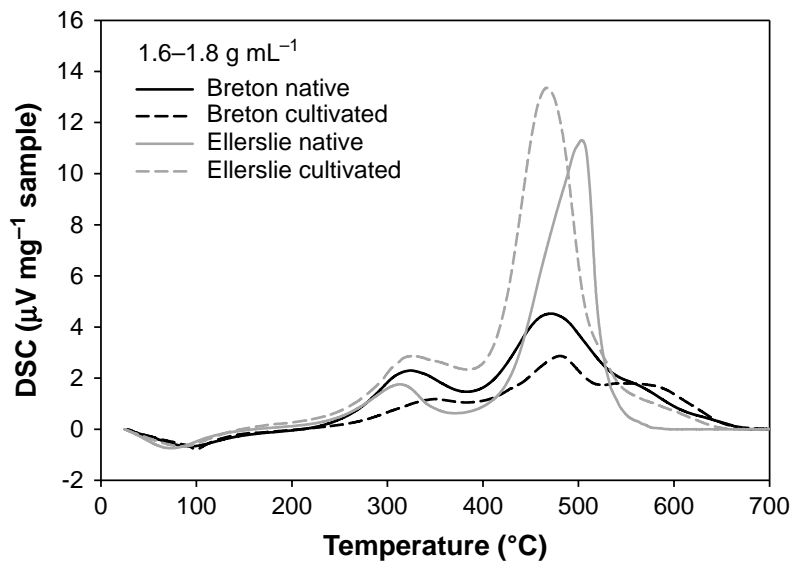

d)

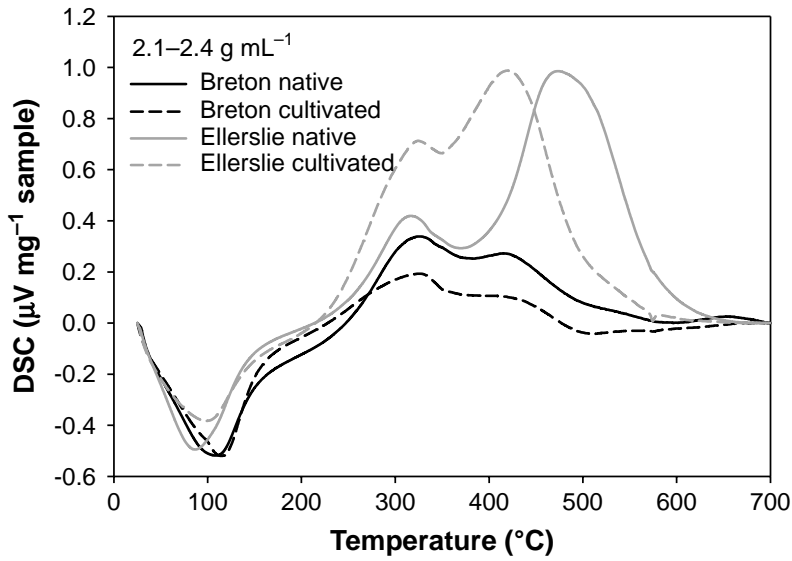

Fig. 8. Differential scanning calorimetry (DSC) thermograms of (a) $1-1.6 \mathrm{~g} \mathrm{~mL}^{-1}$, (b) $1.6-1.8 \mathrm{~g} \mathrm{~mL}^{-1}$, (c) $1.8-2.1 \mathrm{~g} \mathrm{~mL}^{-1}$ and (d) 2.1-2.4 $\mathrm{g} \mathrm{mL}^{-1}$ density fractions from native and cultivated soils from Breton and Ellerslie, Alberta, Canada.

dynamics in density fractions of a Brazilian Oxisol after conversion from cerrado (natural savannah) to pasture, and consistent with many previous observations that particulate and light fraction organic $\mathrm{C}$ is more susceptible to decomposition after the initiation of cultivation (e.g., Cambardella and Elliott 1992). The shift in C distribution from light (1-1.6 and 1.6-1.8 $\mathrm{g} \mathrm{mL}^{-1}$ ) fractions to intermediate (1.8-2.1 and $\left.2.1-2.4 \mathrm{~g} \mathrm{~mL}^{-1}\right)$ fractions was relatively small for the Breton samples, but much more pronounced for the Ellerslie soil samples. The $1.6-1.8 \mathrm{~g} \mathrm{~mL}^{-1}$ fraction represented $\sim 35 \%$ of the whole-soil $\mathrm{C}$ in the native samples in Ellerslie and only $\sim 10 \%$ in the cultivated ones, while in Breton it represented $\sim 10 \%$ of the soil $\mathrm{C}$ before and after cultivation.

In addition to redistributions of mass and $\mathrm{C}$ among density fractions, results of thermal analyses demonstrate that long-term cultivation changed the quality of the organic matter within each density fraction. The most apparent differences in soil organic $\mathrm{C}$ quality due to cultivation were for the lightest fraction $\left(1-1.6 \mathrm{~g} \mathrm{~mL}^{-1}\right)$. The DSC thermograms and $\% \mathrm{Exo}_{1} / \% \mathrm{Exo}_{23}$ values for this fraction differed significantly by land-use treatment, but were similar between Breton and Ellerslie within each treatment (Fig. 8a, Table 3). Temperatures of the largest DSC peak decreased from $\sim 500$ to $450^{\circ} \mathrm{C}$, suggesting a decrease in thermal stability. The large peak at $450^{\circ} \mathrm{C}$ for the light fractions from cultivated soils is indicative of the presence of a cellulose and lignin mixture (Lopez-Capel et al. 2005b). In cultivated samples, a secondary exothermic peak appeared in the $500-550^{\circ} \mathrm{C}$ region, which has been associated with the presence of refractory forms of SOM, such as black C (De la Rosa et al. 2008). These results suggest that after long-term cultivation, this fraction is mainly composed of relatively undecomposed crop residues that are more thermally labile than the light fraction isolated from soils under native vegetation. This can also explain greater $\mathrm{C}: \mathrm{N}$ ratios observed in this fraction for the cultivated samples (Table 2), increases in $\mathrm{Exo}_{\text {tot }}$ mass losses (Table 3), and increases in $\mathrm{C}$ concentrations of this fraction in both soils upon cultivation (from 28.5 to $38.4 \%$ at Breton, and from 24.2 to $40.3 \%$ at Ellerslie, data not shown). The decrease in $\% \mathrm{Exo}_{1} / \% \mathrm{ExO}_{23}$ ratios due to cultivation (which would suggest an apparent increase in stability) is likely due to the arbitrary means of selecting cut-off temperatures for 
$\mathrm{Exo}_{1}, \mathrm{Exo}_{2}$ and $\mathrm{Exo}_{3}$. While a separation of $\mathrm{Exo}_{2}$ and $\mathrm{Exo}_{3}$ at $475^{\circ} \mathrm{C}$ did not make sense for most fractions based on their DSC thermograms (Fig. 8b-d), this separation appears appropriate for the $1-1.6 \mathrm{~g} \mathrm{~mL}^{-1}$ fraction. In this case, cultivation resulted in a significant increase in $\% \mathrm{Exo}_{2}$ and decrease in $\% \mathrm{Exo}_{3}$ for both sites. This is consistent with a decrease in thermal stability after longterm cultivation, as demonstrated by the other results reported above.

Contrary to the $1-1.6 \mathrm{~g} \mathrm{~mL}^{-1}$ fraction, thermograms of the $1.6-1.8,1.8-2.1$ and $2.1-24 \mathrm{~g} \mathrm{~mL}^{-1}$ fractions differed significantly by site, but were similar between native and cultivated treatments within each site (Fig. $8 \mathrm{~b}-\mathrm{d}$ ). At both sites, $\% \mathrm{Exo}_{1} / \% \mathrm{Exo}_{23}$ values for the $1.6-1.8 \mathrm{~g} \mathrm{~mL}^{-1}$ fractions decreased from native to cultivated samples, similar to observations by Lopez-Capel et al. (2005b) for free and intraaggregate light fractions from a silt clay loam Paleudalf converted from grassland to arable soil.

In the intermediate density fractions (1.8-2.1 and 2.1$2.4 \mathrm{~g} \mathrm{~mL}^{-1}$ ), cultivation resulted in different responses for the two soils. Breton samples exhibited a significant decrease in $\% \mathrm{Exo}_{1} / \% \mathrm{Exo}_{23}$ values and relatively similar DSC curves. Ellerslie samples exhibited small increases in $\% \mathrm{Exo}_{1} / \% \mathrm{ExO}_{23}$ values and a decrease in peak temperature for the second (high temperature) DSC peak. These observations suggest that long-term cultivation resulted in organo-mineral complexes of greater thermal stability in the Breton samples and of reduced thermal stability in the Ellerslie samples.

Smaller $\% \mathrm{Exo}_{1} / \% \mathrm{Exo}_{23}$ values and greater $\mathrm{C}: \mathrm{N}$ ratios were observed in the $2.4-2.6 \mathrm{~g} \mathrm{~mL}^{-1}$ fraction in the cultivated soils from both sites, but significant changes in SOM quality due to land-use change are hard to establish because of the small proportion of organic materials and the dominance of mineral components. No significant changes were observed in the heaviest fraction.

Overall, changes in the distribution of mass and $\mathrm{C}$ among density fractions are likely due to the decomposition or accumulation of organic matter associated with mineral particles that result in a change in the density of the particle. While thermal analyses have revealed changes in soil organic $\mathrm{C}$ quality within individual density fraction after long-term cultivation, the mechanisms for these changes are not well understood. Potential mechanisms include organic matter decomposition and transformation within the fraction or transfers among fractions. Additional research using complimentary analytical techniques will be needed to elucidate these mechanisms.

\section{CONCLUSIONS}

Based on a lack of significant differences in clay mineralogy, differences in surface soil $\mathrm{C}$ stocks in the studied soils at Breton and Ellerslie are likely attributable to native vegetation rather than parent material. Different long-term native vegetation also resulted in significant differences in soil organic $\mathrm{C}$ quality between the two sites, as demonstrated by differences in mass and $\mathrm{C}$ distributions after SDF and thermal analyses of whole-soil samples. Similar land use management of these contrasting soils (tillage, crop rotation and residue management, and fertilization) in recent decades has resulted in different soil organic $\mathrm{C}$ losses and redistributions of mass and $\mathrm{C}$ among isolated density fractions and thermal stabilities of these fractions. Long-term cultivation resulted in an overall shift to more stable organo-mineral complexes, but some individual density fractions exhibited a shift to less thermally stable soil organic C, particularly in the Ellerslie soil. The quality of inherited pedogenic soil organic $\mathrm{C}$ stored in a soil thus appears to determine the resulting amount and quality of the soil organic $\mathrm{C}$ remaining after long-term cultivation. While particle density can change due to decomposition or accumulation of associated organic matter, the mechanisms for changes in organic matter quality within density fractions is not well understood and requires further research.

\section{ACKNOWLEDGEMENTS}

The authors wish to thank Darwin Leach from Agriculture and Agri-Food Canada for collection and preprocessing of soil samples, Dick Puurveen from the University of Alberta for continued management of the field plots, Carli Koshal for assistance with laboratory analyses, and Oihane Fernandez for reviewing an early version of the manuscript.

Adams, W. A. 1973. Effect of organic matter on bulk and true densities of some uncultivated podzolic soils. J. Soil Sci. 24: 10-17.

Baisden, W. T., Amundson, R., Cook, A. C. and Brenner, D. L. 2002. Turnover and storage of $\mathrm{C}$ and $\mathrm{N}$ in five density fractions from California annual grassland surface soils. Global Biogeochem. Cycles 16.

Barwood, H. L. and Hajek, B. F. 1979. Differential thermal characteristics of soil and reference quartz. Soil Sci. Soc. Am. J. 43: 626-627.

Basile-Doelsch, I., Amundson, R., Stone, W. E. E., Borschneck, D., Bottero, J. Y., Moustier, S., Masin, F. and Colin, F. 2007. Mineral control of carbon pools in a volcanic soil horizon. Geoderma 137: 477-489.

Bosatta, E. and Ågren, G. I. 1999. Soil organic matter quality interpreted thermodynamically. Soil Biol. Biochem. 31: 18891891.

Cambardella, C. A. and Elliott, E. T. 1992. Particulate organic matter across a grassland cultivation sequence. Soil Sci. Soc. Am. J. 56: 777-783.

Chenu, C. and Plante, A. F. 2006. Clay-associated and claybound organic matter in a cultivation chronosequence: revisiting the concept of the "primary organo-mineral complex". Eur. J. Soil Sci. 57: 596-607.

Crow, S. E., Swanston, C. W., Lajtha, K., Brooks, J. R. and Keirstead, H. 2007. Density fractionation of forest soils: methodological questions and interpretation of incubation results and turnover time in an ecosystem context. Biogeochemistry 85: 69-90. 
Crown, P. H. and Greenlee, G. M. 1978. Guidebook for a soils and land use tour in the Edmonton region, Alberta. In D. F. Acton, and L. S. Crosson, eds. 11th Congress of the International Society of Soil Science, Edmonton, AB.

De la Rosa, J. M., Knicker, H., Lopez-Capel, E., Manning, D. A. C., Gonzalez-Perez, J. A. and Gonzalez-Vila, F. J. 2008. Direct detection of black carbon in soils by Py-GC/MS, carbon-13 NMR spectroscopy and thermogravimetric techniques. Soil Sci. Soc. Am. J. 72: 258-267.

Dell'Abate, M. T., Benedetti, A. and Sequi, P. 2000. Thermal methods of organic matter maturation monitoring during a composting process. J. Thermal Anal. Calorim. 61: 389-396.

Dell'Abate, M. T., Benedetti, A. and Brookes, P. C. 2003. Hyphenated techniques of thermal analysis for characterisation of soil humic substances. J. Separation Sci. 26: 433-440.

Denef, K. and Six, J. 2005. Clay mineralogy determines the importance of biological versus abiotic processes for macroaggregate formation and stabilization. Eur. J. Soil Sci. 56: 469-479.

Denef, K. and Six, J. 2006. Contributions of incorporated residue and living roots to aggregate-associated and microbial carbon in two soils with different clay mineralogy. Eur. J. Soil Sci. 57: 774-786.

Eusterhues, K., Rumpel, C., Kleber, M. and Kogel-Knabner, I. 2003. Stabilisation of soil organic matter by interactions with minerals as revealed by mineral dissolution and oxidative degradation. Organic Geochem. 34: 1591-1600.

Grisi, B., Grace, C., Brookes, P. C., Benedetti, A. and Dell'abate, M. T. 1998. Temperature effects on organic matter and microbial biomass dynamics in temperate and tropical soils. Soil Biol. Biochem. 30: 1309-1315.

Hassink, J. 1997. The capacity of soils to preserve organic C and $\mathrm{N}$ by their association with clay and silt particles. Plant Soil 191: 77-87.

Haynes, R. J. 2005. Labile organic matter fractions as central components of the quality of agricultural soils: An overview. Pages 221-268 in D. L. Sparks, ed. Advances in agronomy. Vol 85. Academic Press, San Diego, CA.

Janzen, H. H. 2005. Soil carbon: A measure of ecosystem response in a changing world? Can. J. Soil Sci. 85: 467-480.

Kaiser, K. and Guggenberger, G. 2003. Mineral surfaces and soil organic matter. Eur. J. Soil Sci. 54: 219-236.

Kramer, M. G., Lajtha, K., Thomas, G. and Sollins, P. 2009. Contamination effects on soil density fractions from high $\mathrm{N}$ or C content sodium polytungstate. Biogeochemistry 92: 177-181. Lopez-Capel, E., Bol, R. and Manning, D. A. C. 2005a. Application of simultaneous thermal analysis mass spectrometry and stable carbon isotope analysis in a carbon sequestration study. Rapid Commun. Mass Spectrom. 19: 3192-3198.

Lopez-Capel, E., Sohi, S. P., Gaunt, J. L. and Manning, D. A. C. 2005b. Use of thermogravimetry-differential scanning calorimetry to characterize modelable soil organic matter fractions. Soil Sci. Soc. Am. J. 69: 136-140.

Mayer, L. M., Schick, L. L., Hardy, K. R., Wagal, R. and McCarthy, J. 2004. Organic matter in small mesopores in sediments and soils. Geochim. Cosmochim. Acta 68: $3863-$ 3872.

Nyborg, M., Solberg, E. D., Malhi, S. S. and Izaurralde, R. C. 1995. Fertilizer N, crop residue, and tillage alter soil $C$ and $N$ content in a decade. Pages 93-99 in R. Lal, et al., eds. Soil management and greenhouse effect. CRC Press Inc., Boca Raton, FL.

Plante, A. F., Pernes, M. and Chenu, C. 2005. Changes in clayassociated organic matter quality in a $\mathrm{C}$ depletion sequence as measured by differential thermal analyses. Geoderma 129: 186-199.

Plante, A. F., Stewart, C. E., Conant, R., Paustian, K. and Six, J. 2006. Soil management effects on organic carbon storage in fractions physically isolated from a Gray Luvisol soil. Can. J. Soil Sci. 86: 141-151.

Roscoe, R., Buurman, P. and Velthorst, E. J. 2000. Disruption of soil aggregates by varied amounts of ultrasonic energy in fractionation of organic matter of a clay Latosol: carbon, nitrogen and delta $\mathrm{C}-13$ distribution in particle-size fractions. Eur. J. Soil Sci. 51: 445-454.

Schmidt, M. W. I., Rumpel, C. and Kögel-Knabner, I. 1999. Evaluation of an ultrasonic dispersion procedure to isolate primary organomineral complexes from soils. Eur. J. Soil Sci. 50: $87-94$.

Shang, C. and Tiessen, H. 2001. Sequential versus parallel density fractionation of silt-sized organomineral complexes of tropical soils using metatungstate. Soil Biol. Biochem. 33: 259 262.

Siewert, C. 2004. Rapid screening of soil properties using thermogravimetry. Soil Sci. Soc. Am. J. 68: 1656-1661.

Sollins, P., Homann, P. and Caldwell, B. A. 1996. Stabilization and destabilization of soil organic matter: Mechanisms and controls. Geoderma 74: 65-105.

Sollins, P., Swanston, C., Kleber, M., Filley, T., Kramer, M., Crow, S., Caldwell, B. A., Lajtha, K. and Bowden, R. 2006. Organic $\mathrm{C}$ and $\mathrm{N}$ stabilization in a forest soil: Evidence from sequential density fractionation. Soil Biol. Biochem. 38: 33133324.

Swanston, C. W., Torn, M. S., Hanson, P. J., Southon, J. R., Garten, C. T., Hanlon, E. M. and Ganio, L. 2005. Initial characterization of processes of soil carbon stabilization using forest stand-level radiocarbon enrichment. Geoderma 128: 5262.

von Lützow, M., Kögel-Knabner, I., Ekschmitt, K., Matzner, E., Guggenberger, G., Marschner, B. and Flessa, H. 2006. Stabilization of organic matter in temperate soils: mechanisms and their relevance under different soil conditions - a review. Eur. J. Soil Sci. 57: 426-445.

Wattel-Koekkoek, E. J. W. and Buurman, P. 2004. Mean residence time of kaolinite and smectite-bound organic matter in mozambiquan soils. Soil Sci. Soc. Am. J. 68: 154-161.

Wattel-Koekkoek, E. J. W., Buurman, P., van der Plicht, J., Wattel, E. and van Breemen, N. 2003. Mean residence time of soil organic matter associated with kaolinite and smectite. Eur. J. Soil Sci. 54: 269-278. 
This article has been cited by:

1. P. Bonnard, I. Basile-Doelsch, J. Balesdent, A. Masion, D. Borschneck, D. Arrouays. 2012. Organic matter content and features related to associated mineral fractions in an acid, loamy soil. European Journal of Soil Science 63:5, 625-636. [CrossRef]

2. Pierre-Joseph Hatton, Markus Kleber, Bernd Zeller, Christophe Moni, Alain F. Plante, Kimberly Townsend, Louisette Gelhaye, Kate Lajtha, Delphine Derrien. 2012. Transfer of litter-derived N to soil mineral-organic associations: Evidence from decadal $15 \mathrm{~N}$ tracer experiments. Organic Geochemistry 42:12, 1489-1501. [CrossRef] 